\title{
Reflections on the Cultivation and Practice of Socialist Core values in Colleges and Universities from the Perspective of Internet Plus
}

\author{
Wang Jiajia ${ }^{1, a}$, Chen $\mathrm{Yu}^{1, \mathrm{~b}}$ \\ 1Taizhou Polytechnic College, Jiangsu Taizhou, China, 225300 \\ awangjiajia_99@163.com bxiaoyueryuchen@163.com
}

Keywords: Internet plus, socialist core values, cultivation and practice.

\begin{abstract}
Cultivating and practicing the socialist core values is the primary mission of colleges and universities. In the Internet age, when planning and promoting the cultivation and practice of socialist core values, we must firmly establish the Internet plus thinking. When the traditional way plug the wings of Internet, it could radiate strong vitality and vigor.
\end{abstract}

\section{Introduction}

For implementing the fundamental task of building up people in higher education, the most important thing is to carry forward the socialist core values, cultivate the builders and successors with the background of Chinese culture and the common ideal of socialism with Chinese characteristics. It must be in a more prominent position.

\section{Cultivating and practicing the socialist core values is the primary mission of colleges and universities.}

Today, the exchange, blending, and confrontation of ideology and culture are becoming increasingly fierce, the ideological consciousness in the market economy is more diverse, changeable, and the battle of values has become the core issue. The quality of values has become a decisive factor. Actively cultivate and practice the socialist core values, together with our own good results, moral judgment and value consensus to forge a powerful ideological weapon. It is increasingly important and urgent to win the ideological battle without gun smoke. Therefore, cultivating and practicing the socialist core values has no choice but to become the primary mission of all education, including higher education.

The socialist core values connect the tradition and reality, link the east and the west, capture the historical classics and the essence of the times, with strong historical nature, reality, sense of the times and foresight. It is the fruit of the fusion of the Chinese outstanding traditional culture and the outstanding achievements of human civilization, and even more the important cornerstone of realizing the sustainable development of the socialist system with Chinese characteristics. As an important base for the training of talents and the advanced heights of ideological and cultural construction, colleges and universities are not only responsible for training qualified constructors and reliable successors of socialism, but also responsible for advocating, spreading and leading various new ideas and new ideas. Concentrate socialist core values, it is no doubt the first inevitable choice to a new era.

Judging from the objective law of the growth of talents, morality is the foundation of being a man, the guarantee of becoming a talented person and the most important quality. Only according to the standards of both morality and talent can students be trained. As General Secretary Xi Jinping has pointed out, the socialist core values are the foundation of virtue: "The core values are in fact a kind of virtue, which is not only the virtue of individual, but also a kind of great virtue, that is, the virtue of the country, the virtue of the society. " At the same time, noble teacher morality is the endogenous motive force for the cultivation of talented people. In order to cultivate virtuous people, teachers and staff must have virtue first. Although the Internet has brought great convenience to people, it is also 
has a series of negative effects. It would not only have a negative influence on teachers' and students' thoughts, morality, psychology and character, but also mislead students in politics. To cultivate and practice the socialist core values, it is an important mission and fundamental task for colleges and universities to use our party's consensus on the values of the whole party and the whole society to guide teachers, students and staff in their network life, to correct the disorder, and to clear up the root causes. Colleges and universities must consciously take cultivation and practice the socialist core values as their primarymission, always run through the whole process of the development of the cause, and make the socialist core values take root and blossom and bear fruit, naturally blend into the learning, working, living and spiritual world of the vast number of teachers and students.

\section{Cultivating and practicing of core values based on Internet plus thinking is the necessity of the times.}

The cultivation and practice of socialist core values is a huge, long-term system engineering, involving all aspects, it needs comprehensive planning, coordination, overall promotion, collaborative innovation, otherwise it will inevitably be overstretched, and difficult to sustain. ${ }^{[1]}$ For colleges and universities, we must pay attention to plan and study the process and path of cultivating and practicing the socialist core values. Only by making fundamental thinking and designing the workflow of cultivating and practicing the socialist core values, carefully making a good choice of the path, only by constantly innovating ways and methods, exploring effective forms and forming a long-term mechanism, the cost, quality and efficiency of the system project of cultivating and practicing the socialist core values could be greatly improved, so that we would achieve both qualitative and quantitative double jump in overall job performance.

However, no matter whether it is the design of cultivation and practice process or the choice of path, we must strictly follow the laws of education and training of talents, and all must conform to the internal and objective laws of the development of higher education. It is possible to establish accurately the overall purpose and specific goal of cultivating and practicing the socialist core values, to truly achieve the purpose calling, the goal leading, and have a clear implementation path. ${ }^{[2]}$ At present, the society has entered a new era, the network has changed the interaction mode of people, especially the rapid emergence of various new media platforms, breaks the boundaries of time and space, occupied people's time. Once on the horizon, now in the corner, Internet life has become a basic way of life. It produces an extensive, profound and long-term effects of ideals, beliefs, ways of thinking, modes of behavior, mental health, and so on, for all netizens, including teachers and students in colleges and universities, especially young college students. So, when planning and promoting the cultivation and practice of the socialist core values, we must firmly establish the Internet plus thinking. Of course, to establish the Internet plus thinking, not just focus on the Internet, but do not care about the offline, that will put the cart before the horse. We should pay attention to the online as well as offline, the two should be pushed forward in a coordinated manner.

It is the inevitable requirement of the new era to plan and promote the cultivation and practice of the socialist core values by Internet plus thinking. It is necessary to take "establishing morality and creating people" as the overall purpose, which runs through the integration and innovation of Internet plus thinking and traditional thinking at all times. The specific characteristics of higher education, the connotation of the times and the objective reality of colleges and universities must be carefully analyzed. On the basis of this, the specific goals of cultivating and practicing the socialist core values in colleges and universities are further defined: the long-term goals, the medium-term goals, the short-term goals, sub-objective etc. Only by closely focusing on the overall objectives and these specific goals we could find the most effective way for colleges and universities in the Internet plus era to cultivate and practice the core values of socialism, and we could truly achieve the overall advancement and orderly convergence, point to face, highlight the key, so that achieve twice the result with half the effort. 


\section{The main path of cultivating and practicing socialist core values under Internet plus thinking.}

\subsection{Enhanced top-level design}

To establish and improve the leadership system and working mechanism, according to the reality of the study, work and life of teachers and students in colleges and universities in the Internet era, as well as the integration of online and offline, to refine the relevant requirements of socialist core values into specific provisions, to conscientiously study and formulate evaluation and assessment systems, establish incentive mechanisms, regulations for rewards and punishments, and other rules, concretize the content of core values in the form of norms of words and deeds, standards of implementation, etc. First, we should formulate and issue "Opinions on Cultivating and Practicing Socialist Core Values" in time according to the changes in the actual situation in the network age, and clearly cultivate and practice carrying out the guiding ideology, basic principles, basic adherence and approach measures of socialist core values. Second, we should adhere to the socialist core values to lead the construction of campus culture, the construction of teacher ethics and teacher style, and the ideological and political education of students, in the light of the reality of running a university. Consciously integrate the core values into the development of colleges and universities and the daily life of teachers and students.

\subsection{Strengthen classroom education}

To promote the socialist core values into teaching materials, into the classroom and into the minds of students, so as to refine them into the requirements of students' core literacy, to integrate them into the whole process of education and teaching, and to implement all aspects of education and teaching. First is to firmly grasp the ideological and political class. Regarding the socialist core values as an important content of the ideological and political class teaching, we should make a good explanation of the basic connotation and profound meaning, explain and publicize the education, and combine the characteristics of the body and mind of the college students and the law of growth, strengthen the positive guidance of social hot and difficult issues, enhance the attraction and appeal of ideological and political education. Second, make full use of specialized courses, pay attention to the curriculum design and teaching guidance of various specialized courses, and vigorously explore the cultural connotations of specialized courses. The core values education should be permeated into all kinds of curriculum teaching, and integrated into every link of students' study, which makes students have strong approval in the process of imperceptibly changing.

\subsection{Strengthen carrier construction}

Pay attention to make good use of all kinds of carriers and positions, strive to realize the lives, concretize construction of the core values, make it become the basic follow of the daily life of teachers and students. First, bring the practice of core values into the appraisal of party members and league members, to actively organize and carry out related theme Party Day and League Day activities. Party schools at all levels and league schools take it as an important part of the education and training of party members, party activists, development objects and league members. Second, it is necessary to establish and standardize a number of etiquette systems with rich connotations. To carry out solemn ceremonies, make full use of traditional national festivals, major anniversaries, and carry out educational activities to carry forward mainstream values. Third, we should pay attention to strengthening the construction of information content on campus networks. We should strengthen the positive propaganda and comment on the Internet, carry out healthy network cultural activities, promote the civilized use of the Internet, sing the main melody of the Internet, and vigorously create a clear network space.

\subsection{Strengthen practice cultivation}


Closely revolve around social morality, professional ethics, family virtue, personal morality, guide and organize teachers and students to start from small things, from the side of things, improve self-discipline awareness, strengthen self-education, consciously achieve to cultivate oneself, to think of the good, to be virtuous and to be kind, to be tolerant of comity. First is to actively advocate honesty, respect for credit, keep promises, guide teachers and students to set up the concept of honor to keep one's word, shame to break one's word, be honest people, do things with good faith, praise good faith, punish the breach of promises, to create an honest and trustworthy campus atmosphere, to promote teachers and students to influence each other, to promote each other, to act in practice. Second is to implement the spirit of Lei Feng and the spirit of voluntary service of "dedication, fraternity, mutual assistance and progress". To actively organize and carry out various forms of volunteer service activities to learn from Lei Feng, and to clarify the requirements of each university student to participate in all kinds of voluntary service and other ethical practices, so as to guide the majority of students in sublimation of cognitive understanding in moral practice of serving others and dedication society.

\subsection{Strengthen atmosphere construction}

To strengthen publicity and education, promote the theory identity and emotional identity of teachers and students. First, to take the study of socialist core values of education into schools, branches (departments) two level center group and party learning plan, guide and standardize the academic behavior, adhere to the academic integrity, maintaining academic morality. Second is to do a good job of freshmen's entrance education and graduate civilized leaving school education, carry out various forms, regular study style construction activities, to cultivate students the good character of paying attention to the credit, keeping the promise, and stressing the good faith. Third is to carry out the traditional culture, the elegant art and clean government culture into the campus and other activities, and the core values into the spiritual culture, material culture, system culture and behavior culture, in full play to the role in nurturing campus culture education of people gradually.

In the age of the Internet, we must pay attention to the effective interaction between the online and offline. We should make full use of all kinds of traditional ways and new media technologies to enable the campus network, college newspapers, radio stations, publicity boards and LED display screens, school windows, blackboard newspapers, WeChat, Weibo, mobile phone client and other carriers fusion, so that the traditional way could plug in the wings of the Internet, radiate a more powerful vitality and vitality, promoting the influence of the core values like the air everywhere, always.

\section{Acknowledgement}

This article was financially supported by the Special Project of Ideological and Political Work on the Research of Philosophy and Social Science in Universities of Jiangsu(2017SJBFDY683), the Key Project of Scientific Research Fund of Taizhou Polytechnic College (TZYKYZD-17-4).

\section{References}

[1] Wang Xiaoxi. The Construction of Civil Morality in China from the Perspective of System Engineering[J], Xinhua Digest, 2014, (15). A. Banerjee, A joint economic-lot-size model for purchaser and vendor, Decision Sciences, vol.17, pp. 292-311, 1986.

[2] Yang Zhiping. Finding the Path of Core Value Education[N], Guangming Daily, 2013-02-23. 